\section{Poner la casa (oĩkos) en orden: reconfiguración de relaciones en la Carta a Filemón*}

\author{
Mary Betty Rodríguez-Moreno ${ }^{\mathrm{a}}$ \\ Pontificia Universidad Javeriana, Colombia \\ https://orcid.org/0000-0003-1028-269X
}

Resumen: El artículo busca esclarecer algunos de los interrogantes recientes propuestos por los investigadores de la Carta a Filemón. En diálogo estrecho con los estudios socioculturales del mundo mediterráneo y el análisis retórico de la Carta, buscamos demostrar cómo la retórica paulina reconfigura los principios básicos de las relaciones humanas de la casa y de la Iglesia a partir de la experiencia vivida en la casa de Filemón con su esclavo Onésimo. La Carta significó seguramente una gran novedad para los miembros de esta iglesia doméstica, dadas las condiciones socioculturales constitutivas de su escenario de lectura.

Palabras clave: Teología paulina; Carta a Filemón; esclavitud; relaciones sociales en el Nuevo Testamento.

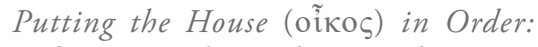
Reframing Relationships in the Letter to Philemon

Aвstract: The article tries to clarify some of the recent topics that researchers of the Letter to Philemon have proposed. In close dialogue with the socio-cultural studies of the Mediterranean world and the rhetorical analysis of the Letter, we seek to demonstrate how Pauline rhetoric reframes the basic principles of human relationships within the house and the Church, based on the experience lived in Philemon's house, regarding his slave Onesimus. The Letter probably meant a great novelty for the members of this domestic church, given the sociocultural conditions of its reading scenario.

Key Words: Pauline Theology; Letter to Philemon; Slavery; Social Relations in the New Testament.

\begin{abstract}
Cómo CITAR:
Rodríguez-Moreno, Mary Betty. "Poner la casa (oĩ relaciones en la Carta a Filemón". Theologica Xaveriana (2020): 1-19. https://doi. org/10.11144/javeriana.tx70.pcorr
\end{abstract}

\footnotetext{
* Artículo derivado del proyecto de investigación en curso del doctorado en Teología.
}

${ }^{a}$ Autor de correspondencia. Correo electrónico: mary.rodriguez@javeriana.edu.co 


\section{Introducción}

¿Cómo busca persuadir Pablo a sus interlocutores en la Carta a Filemón? Estudios recientes han profundizado, primero, en las técnicas retóricas utilizadas por el Apóstol en esta Carta, y segundo, en las ambigüedades e incongruencias evidenciadas por el análisis epistolar ${ }^{1}$.

Con relación a la primera cuestión, los estudiosos se preguntan si Pablo propone una verdadera propositio (o tesis) así como una probatio (o serie de pruebas) en tan poco espacio ${ }^{2}$. ¿Acaso una Carta tan breve se puede tratar como un discurso de la Antigüedad?

Con relación a la segunda cuestión, los investigadores se preguntan por qué Pablo incluye entre sus destinatarios a una mujer ${ }^{3}$, un "compañero de lucha"

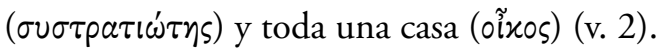

Si la Carta tenía un motivo personal-como indica su destinatario $(\Phi \iota \lambda \eta \dot{\eta} \mu \circ v \iota \tau \tilde{\omega}$ à $\alpha \pi \eta \tau \tilde{\omega})($ v. 1)-, ¿para qué añadir "la Iglesia que se reúne en esa casa" (v. 2)? Pablo pide en favor de Onésimo, literalmente "hijo generado en cadenas" (v. 10). Ahora, nunca dice explícitamente qué pide para él; en el v. 17b, el Apóstol pide a Filemón que lo reciba "como a mí mismo". Sin embargo, no queda claro si se trata de acogerlo después de su fuga (interpretación tradicional), si se trata de recibirlo después de ser rechazado por Pablo (interpretación clientelista), o si se trata de recibirlo en sentido muy amplio por caridad cristiana (interpretación general).

El presente artículo busca esclarecer algunos de los interrogantes recientes propuestos por los investigadores de la Carta. En diálogo estrecho con los estudios socioculturales del mundo mediterráneo y el análisis retórico de la Carta, buscamos demostrar cómo la retórica paulina reconfigura los principios básicos de las relaciones humanas - de la casa y de la iglesia-, a partir de la experiencia vivida en la casa de Filemón, con su esclavo Onésimo. La Carta significó seguramente una gran novedad para los miembros de esta iglesia doméstica, dadas las condiciones socioculturales constitutivas de su escenario de lectura.

En el mundo grecorromano, la unidad básica de relación era la casa (oĩxos), organizada jerárquicamente y regida por un varón libre conocido como el paterfamilias,

\footnotetext{
${ }^{1}$ Elliott, “'Thanks, but no Thanks': Tact, Persuasion, and the Negotiation of Power in Paul's Letter to Philemon", 51-64.

2 Pitta, "Come si persuade un uomo? Analisi retorico-letteraria della lettera a Filemone", 93-107.

${ }^{3}$ Esta es la única carta cristiana que menciona a una mujer como destinataria, seńalando, de hecho, el rol que ellas tenían en la comunidad cristiana naciente; distinto, al parecer, de su rol habitual en el Imperio. Véase a Osiek, MacDonald y Tulloch, El lugar de la mujer en la Iglesia primitiva, 207-208.
} 
cabeza de familia. El término "familia" comprendía una red amplia de relaciones que no estaba definida únicamente por la consanguinidad, por lo cual no se puede disociar la "oĩxos, domus" de sus habitantes. En ella, las relaciones habituales eran de subordinación: amo-esclavo, hombre-mujer, hombre/padre-niño/hijo ${ }^{4}$. El esclavo y el niño-hijo se consideraban propiedad del amo-padre, y la mujer, aunque en menor proporción, también pertenecía al varón. Los esclavos estaban en el ámbito rural y doméstico o urbano.

El cabeza de familia gobernaba la casa en función de las actividades productivas, que finalmente estaban en manos de los esclavos. Al ser la casa-familia un espacio para vivir y del que vivir, se convertía en un escenario de gran dinamismo económico 5 . Los estudios recientes de la Carta se preguntan si la mención de la iglesia que se reúne o encuentra en la casa de Filemón constituye un indicio decisivo para interpretar la Carta como una exhortación sutil, pero suficientemente persuasiva, retóricamente hablando, a reconfigurar las relaciones socioculturales características de la casa grecorromana.

En el mundo grecorromano, los esclavos domésticos tenían un nivel de vida más elevado que los rurales, y podían además conseguir la libertad. En dependencia del tipo de amo que tuviera el esclavo, variaba su forma de trabajo, su nivel de vida y su estatus en la sociedad. La esclavitud se consideraba connatural a la existencia y el esclavo era visto como un objeto, propiedad de un amo, sin condición legal ni derecho social $^{6}$. El número de esclavos en la casa-familia dependía de los medios económicos de esta; incluso las familias pobres podían poseer un esclavo, más exactamente una esclava, quien debía realizar todos los trabajos: era portera, limpiadora, cocinera, camarera y hasta servidora sexual ${ }^{7}$.

A diferencia del mundo grecorromano, en el mundo de la Biblia -más exactamente en los códigos legales de los libros del Éxodo, Levítico y Deuteronomio- se presenta una imagen bastante distinta de la esclavitud. En Dt 5,12-18, por ejemplo, se propone una interpretación nueva de la condición del esclavo. A diferencia de Ex 21,1-11, en Dt 15,12 no solo se le llama "hebreo" sino "hermano". La legislación del Deuteronomio introduce, además de esta perspectiva fraterna, condiciones de

\footnotetext{
${ }^{4}$ Miquel, Qué se sabe del Nuevo Testamento desde las ciencias sociales, 118-121.

${ }^{5}$ Fernández Vega, La casa romana, 461.

${ }^{6}$ En el mundo grecorromano antiguo, la esclavitud formaba parte de la vida y la organización del Estado, y los esclavos constituían la fuerza de trabajo y producción. Véase a De Vaux, Instituciones del Antiguo Testamento, 125; y a Phillips, La esclavitud desde la época romana hasta los inicios del comercio transatlántico, 9 .
}

${ }^{7}$ Fernández Vega, La casa romana, 459-460. 
igualdad para esclavos y esclavas. "El código deuteronómico insiste en la fraternidad y la solidaridad que debe unir a todos los miembros del pueblo de Israel".

En el libro del Levítico, la legislación de Israel va más allá. Lv 25,39-43 establece que el "hermano", si tiene que saldar deudas y se vende como esclavo, no se ha de tratar como tal sino como un jornalero o huésped, y no se le impondrán trabajos de esclavo. Así, para el Levítico queda abolida la esclavitud entre el pueblo de Israel'?

Los estudios de la Carta a Filemón se preguntan, todavía, si Pablo o Filemón conocían la legislación del Antiguo Testamento en relación con los esclavos, y si ello es así, ¿por qué el Apóstol no aduce ninguna prueba de las Sagradas Escrituras para procurar la libertad de Onésimo? ¿Acaso la retórica paulina busca persuadir a sus destinatarios en una dirección diferente a la del Antiguo Testamento, conservando paradójicamente el statu quo de la esclavitud en el mundo grecorromano?

El doble escenario de lectura apenas propuesto, a saber, el ámbito de la casa y la realidad de la esclavitud, característicos del mundo grecorromano, servirá en seguida de marco hermenéutico para la exégesis de la Carta a Filemón. En las páginas siguientes se propone una close reading de la Carta que busca esclarecer los siguientes interrogantes: (1) ¿Cómo busca persuadir Pablo en su Carta? (2) ¿Cuál es la transformación efectiva que él propone de la esclavitud? (3) ¿Qué tipo de reconfiguración de las relaciones de la "casa-familia grecorromana" sugiere a fin de cuentas en su demostración retórica?

\section{Estructura de la carta a Filemón}

La forma literaria de la Carta a Filemón corresponde al "fondo parenético de la tradición" ${ }^{10}$, perfilada de acuerdo con los ideales cristianos que han de vivirse en el ambiente cotidiano de la iglesia doméstica ${ }^{11}$. El texto corresponde a la estructura de

\footnotetext{
${ }^{8}$ Ska, Introducción a la lectura del Pentateuco. Claves para la interpretación de los cinco primeros libros de la Biblia, 68.

${ }^{9}$ Al respecto, según Ska: "La reglamentación del Levítico trata, como el código del Deuteronomio, de las personas que tienen que 'venderse' para saldar deudas y de su liberación. Hay una gran diferencia con las normas precedentes: la prescripción del Levítico realmente abole la esclavitud entre el pueblo de Israel. Quien tenga que saldar deudas es tratado como asalariado o residente, no como esclavo ('ébed). Como dice expresamente Lv 26,39-40" (ibíd., 70).

${ }^{10}$ Zimmermann, Los métodos histórico-criticos en el Nuevo Testamento, 175-176.

${ }^{11}$ De acuerdo con el contenido de la Carta, Pablo se encuentra en prisión (Flm 1.9.10). Su encarcelamiento se sitúa con gran probabilidad en Éfeso. Véase a Crossan y Reed, En busca de Pablo, 329; Fitzmyer, “Carta a Filemón” 420; Miguez, "Carta a Filemón”, 1043; y Pastor, Corpus paulino II, 198.
} 
la Carta antigua ${ }^{12}$ y en ella también se distingue la retórica aplicada a las cartas. Por ello se tendrá presente la estructura retórica de la Carta, así:

Saludo. Vv. 1-3

Exordium. Oración de acción de gracias y captatio benevolentiae (vv. 4-7)

Propositio. Una apelación con base en el amor (vv. 8-11)

Probatio. La razón para el regreso (vv. 12-16)

Peroratio. Renovación (vv. 17-22)

1. Bienvenida, regreso (vv. 17-19; incluye la mención de la firma de Pablo, en el v. 19).

2. Último motivo (vv. 20-21), una petición final ${ }^{13}$.

Esta estructura visualiza cómo Pablo propone a Filemón y a la iglesia que se reúne en su casa-familia nuevas formas de relacionarse basadas en la igualdad humana en Cristo.

\section{Saludo}

Pablo prisionero de Cristo Jesús y Timoteo, el hermano, a nuestro querido y colaborador Filemón, a la hermana Apia, a nuestro compañero de armas, Arquipo, y a la iglesia que se reúne en tu casa.

En estos versículos se menciona la comunidad y su presencia es relevante como testigo (testimonio) de la propuesta que Pablo hace a Filemón ${ }^{14}$. De igual manera, los términos familiares ( $\dot{\alpha} \gamma \alpha \pi \eta \tau \tilde{\omega}, \sigma u \nu \varepsilon \rho \gamma \tilde{\omega}, \dot{\alpha} \delta \varepsilon \lambda \phi o ́ s, \dot{\alpha} \delta \varepsilon \lambda \phi \tilde{n}:$ amado-querido, compañero, hermano, hermana) profundizan más en el vínculo de cercanía y familiaridad entre Pablo y sus destinatarios.

12 (A) Introducción (1-3): saludo. (B) Acción de gracias: Pablo da gracias a Dios por la fe y el amor de Filemón (4-7). (C) Cuerpo: Pablo apela a la buena voluntad de Filemón para que reciba bien a Onésimo e insinúa lo útil que le es (8-22); está dividido en dos partes: (1) Intercesión por Onésimo (8-16), en la que apela al fundamento del amor (8-11) y razón para el regreso de Onésimo (12-16); y (2) Epilogo-resumen final (17-22). (D) Conclusión: saludos de los compañeros y bendición (23-25).

${ }^{13}$ Witherington, The Letters to Philemon, the Colossians and the Ephesians. A Socio-Rhetorical Commentary on the Captivity Epistles, 19.

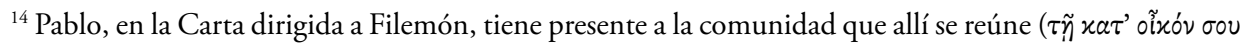

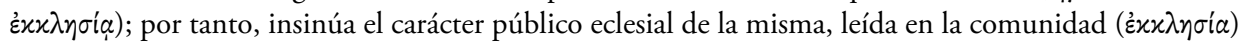
cristiana que se reunía en la casa (oĩxos) de Filemón. 
Al saber que el término "hermano" es típico del judaísmo, usado para los correligionarios $^{15}$, Pablo señala o quizás le recuerda a la comunidad que la fraternidad es fundamento cristiano; Cristo constituye el vínculo entre ellos. Pablo, por medio del término (åd $\delta \lambda \phi o ́ \varsigma)$, expresa la condición que comparten quienes han creído en Jesucristo ${ }^{16}$ como la nueva identidad típica del cristianismo naciente, señalando que las nuevas relaciones se dan en Cristo y que el hermano no es solo el correligionario, ni aquel que comparte la condición social (amo o esclavo).

La palabra hermano, hermana se menciona cuatro veces en la Carta y una en

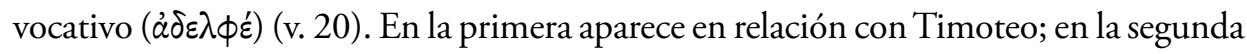
con respecto a Filemón; la tercera en el v. 16, para señalar la igualdad de fraternidad entre Onésimo (esclavo) y Filemón (amo-señor), y la cuarta es en relación con Apia, a quien llama "hermana" (ả $\delta \varepsilon \lambda \phi \tilde{n})$ (v. 2).

El hecho de reconocer a Apia como "hermana” cambia la concepción y el lugar tradicional como esposa de Filemón, pues en ese pequeño detalle Pablo reconoce el rol que ella tiene en la comunidad, pues la nombra en las mismas condiciones, con Timoteo y Filemón. Quiere decir que en el interior de la iglesia Apia seguramente no está en la lógica de subordinación propia del mundo grecorromano.

Al contrario, el carácter de hermana evidencia las condiciones de igualdad y horizontalidad propuestas por Pablo en Jesucristo ${ }^{17}$. Apia, reconocida como hermana, sugiere que la iglesia y la vida social cristiana tienen un nuevo proyecto en la configuración de la iglesia doméstica. Esta es la única carta cristiana que menciona a una mujer como destinataria, señalando el papel de las mujeres en la comunidad cristiana naciente, distinto a la concepción del imperio.

\section{${ }^{3}$ Gracia y paz a ustedes, de Dios nuestro Padre y del Señor Jesús Cristo.}

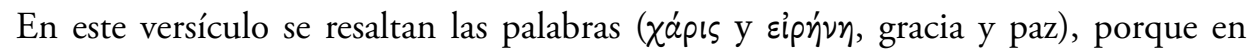
ellas se fundamenta el trasfondo judío y cristiano del pensamiento paulino, especialmente de la palabra "gracia", cuyo concepto supera las comprensiones de la tradición

\footnotetext{
${ }^{15}$ En el mundo judío se utilizaba el término "hermano" para indicar al correligionario que históricamente también era compatriota. Hay dos textos que respaldan el uso que se hacía en el mundo judío del término $\alpha \dot{\alpha} \varepsilon \lambda \phi o ́ s:$ por un lado, "hermano carnal" según la LXX en Gn 43, 3; por otro, se refiere al pueblo en

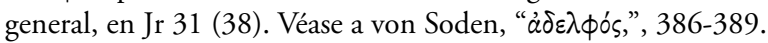

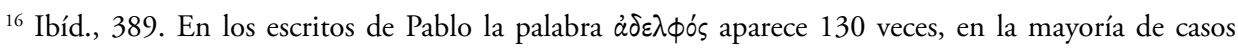
relacionada con ser cristiano.

${ }^{17}$ En la Carta a los Gálatas, las distinciones que excluyen y subordinan han desaparecido en Cristo (Ga 3,27-28). No se desconoce que, tradicionalmente, a Apia se le considera esposa de Filemón. J. D. Crossan y M. J. Borg dejan en interrogante esa denominación (Borg y Crossan, El primer Pablo. La recuperación de un visionario radical, 40 ).
} 
grecorromana del sistema de patronazgo o clientelismo. En esta línea, se encuentra que para Pablo la gracia ( $\chi a ́ p ı s)$ es un concepto central, en el que se expresa la mejor forma

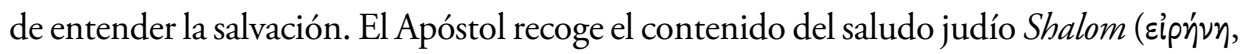
paz) ${ }^{18}$ que desea el bien y abarca los mejores deseos en Dios para los destinatarios.

\section{Exordium. Oración de acción de gracias y captatio benevolentiae (vv. 4-7)}

${ }^{4}$ Doy gracias a mi Dios siempre mencionándote en mis oraciones, ${ }^{5}$ escuchando de ti el amor y la fe, que tienes hacia el Señor Jesús y hacia todos los santos. ${ }^{6} \mathrm{~A}$ fin de que tu participación en la fe se haga eficaz mediante el conocimiento de todo lo bueno que hay en nosotros para Cristo. ${ }^{7}$ Pues tuve gran alegría y consuelo en tu amor, porque las entrañas de los santos han sido reconfortadas por ti, hermano.

En este apartado se observa cómo Pablo -a través del discurso retórico- quiere mostrar a los destinatarios el conocimiento cercano que tiene de Filemón (sin que este sea su principal objetivo), disponiendo el discurso de tal manera que logre persuadir a los oyentes. Así, es evidente el uso paulino del arte retórico, específicamente del exordium, en el que -con una captatio benevolantiae- logra captar la atención de sus destinatarios ${ }^{19}$.

Aquí se encuentra la acción de gracias ${ }^{20}$, habitual en este tipo de carta, que introduce su cuerpo y propone de forma relevante los temas a tratar. La acción de gracias puede ser un medio de enseńanza para los oyentes; se dirige a Filemón, pero le habla a la comunidad, pues ella también ha de asumir la petición paulina. El Apóstol utiliza el recurso retórico de la captatio benevolente, con el fin de suscitar la

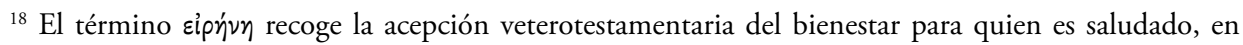
este caso para los miembros de la "casa" (oĩxos). Es el Shalom, que forma parte de la tradición judía,

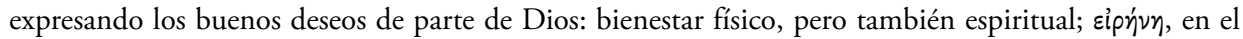
Nuevo Testamento, se refiere a un buen estado espiritual y físico en la persona que, como resultado, da

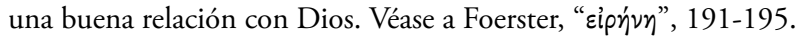

19 Es un elogio por un motivo importante, en este caso, al destinatario de la Carta.

${ }^{20}$ En la acción de gracias inicial sobresale el pronombre posesivo de primera persona singular referido a

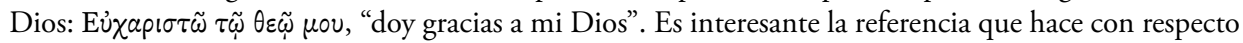
a él, aun cuando emplea la misma expresión en otras cartas, por ejemplo, en Rm 1,8 o en Flp 4,19. La relación de pertenencia puede estar indicando, por un lado, el trato profundo con Dios o la especificación del Dios de Jesucristo. "Mi Dios", por otro lado, puede estar aclarando a qué Dios se refiere, teniendo en cuenta el contexto religioso del mundo romano y la diversidad de dioses y creencias que en él se podían encontrar. Sin embargo, creemos que el uso del pronombre posesivo está reforzando las palabras de Pablo en cuanto indican su relación profunda con Dios y con Jesucristo. Esta mención del Dios de Jesucristo podría indicar, además, el paso al monoteísmo, que en una comunidad formada por hombres y mujeres venidos del mundo grecorromano tuvo que ser progresivo. Así, especificar "a mi Dios" podría estar centrando la nueva fe adquirida por Filemón y la iglesia que en su casa se reunía. 
compasión de Filemón ${ }^{21}$ : le habla de su caridad, de su fe (v. 5) y le llama "hermano" (v. 7), sin olvidar la presencia de la comunidad que está escuchando.

Mediante las expresiones positivas ("tu caridad", "tu fe", en los vv. 5-6) referidas a Filemón (captatio benevolentiae), Pablo atrae su atención y buena disposición, para poder pedirle posteriormente aquello que desea. Aquí el uso del discurso epidíctico, en correspondencia con la retórica, no busca una persuasión racional, por medio de una serie de recursos y argumentos, sino una proclamación autoritativa, que se apoya en factores como la misma fuerza del mensaje o la autoridad de quien lo transmite que en este caso es $\mathrm{Pablo}^{22}$.

\section{Propositio. Intercesión por Onésimo (vv. 8-11]}

${ }^{8}$ Por eso, aunque tengo en Cristo mucha libertad para mandarte lo que conviene, ${ }^{9}$ más bien prefiero rogarte en nombre del amor, yo Pablo un anciano y ahora un prisionero de Cristo Jesús. ${ }^{10}$ Te ruego por mi hijo a quien engendré en las prisiones, Onésimo, ${ }^{11}$ que en otro tiempo te fue inútil, pero ahora muy útil para ti y para mi.

Los versículos 8-16 son una unidad temática que constituye el marco concreto de la petición de Pablo a Filemón. De hecho, en el versículo 17 aparece un cambio de nivel sintáctico y de contenido ${ }^{23}$. Esta unidad comienza en el v. 8 porque, aun cuando la temática que se deriva va unida a la anterior, los argumentos que se desarrollan en este apartado son nuevos. Sin embargo, la sección se divide en dos bloques, teniendo en cuenta la argumentación retórica y sus recursos: en primer lugar, se encuentra la propositio, donde Pablo expone sus argumentos a Filemón (vv. 8-11); y en segundo lugar la probatio, donde desarrolla la validez de los argumentos usados.

La partícula $\delta$ ió vincula el versículo 8 con la acción de gracias que aparece en los vv. 4-7, de forma causal, subrayando la secuencia narrativa y argumentativa con lo expuesto previamente. Así, Pablo, a partir de lo dicho en los vv.4-7, tiene motivos para

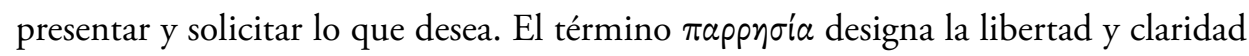
con que Pablo se dirige a Filemón. Además, esta palabra se relaciona con la confianza que el Apóstol siente hacia Dios; en el fondo, él no duda de la autoridad de su palabra, pues tiene su cimiento en Cristo. Esta confianza o seguridad ya aparece formulada en 2Co 3,12, como en Flm 1,20, con referencia a Cristo.

\footnotetext{
${ }^{21}$ Caballero, "Retórica y teología. La Carta a Filemón”, 449.

${ }^{22}$ Ibíd., 444.

${ }^{23}$ Ibíd., 451.
} 


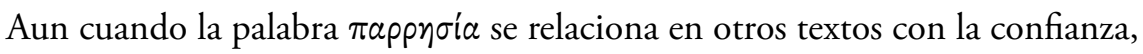
claridad, libertad y seguridad, en este caso está profundamente unida al sentido de "autoridad". Ella indica la libertad y seguridad que tiene Pablo en Cristo; esta le da autoridad frente a la comunidad y frente a Filemón.

Filemón tendría que obedecer de hecho a Pablo, movido por su autoridad e importancia en la comunidad. Sin embargo, Pablo desea que Filemón actúe por otras razones, motivado por su libertad y por su fe en Cristo, como lo precisa en seguida (v. 9) ${ }^{24}$. Pablo busca que Filemón realice una acción de acuerdo con el ideal cristiano; este sería el sentido de $\tau o ̀$ à $\nu \tilde{\eta} x o \nu^{25}$. No obstante, como él mismo dice, no quiere obligar a Filemón a actuar como él le está pidiendo, sino que apela a los valores fundamentales que caracterizan al cristiano (la fe y el amor). De esta forma, entonces, Pablo busca persuadir a Filemón a que actúe según la vida en Cristo.

En el v. 9, el verbo $\pi a p a x a \lambda \tilde{\omega}$ (ruego o suplico) está unido a la argumentación del v. 8, pues la súplica de Pablo busca que Filemón actúe libremente por amor. En

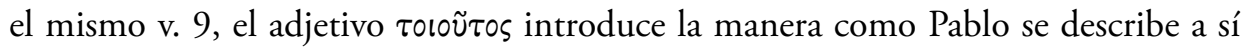
mismo: anciano y prisionero de Cristo. Ya en 1Co 3,10, Pablo se caracteriza de igual modo $^{26}$. Esta definición de sí mismo corresponde a la demostratio, y expone de forma viva y detallada la realidad en la que posiblemente se encuentra. Este recurso retórico le sirve a Pablo para ejercer cierta presión "psicoafectiva" sobre Filemón y enseñarle de este modo hasta dónde se ha de llegar por Cristo.

Después de los argumentos utilizados en los vv. 8 y 9, Pablo formula de manera

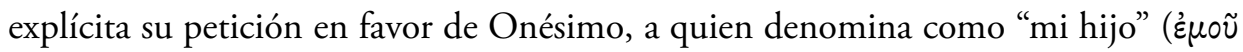

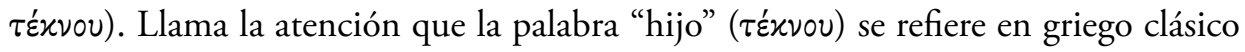
a la idea de nacimiento; en el Nuevo Testamento tiene un sentido más amplio, más allá del parentesco de sangre. En esta Carta, el término indica la filiación espiritual; también sugiere la relación entre el maestro y el discípulo ${ }^{27}$.

En Pablo, la misma expresión se refiere a quienes él ha evangelizado, como se

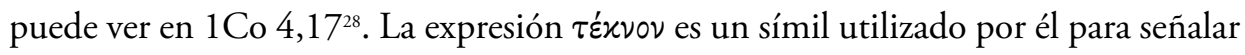
el vínculo que ha creado con la persona evangelizada. De ahí que se sienta como padre

${ }^{24}$ Lohse, Colossians and Philemon, 198.

${ }^{25}$ Lo que conviene, lo apropiado.

${ }^{26}$ Lohse, Colossians and Philemon, 199.

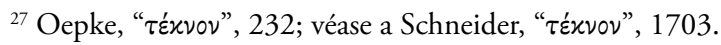

${ }^{28}$ Así mismo lo retomará la tradición deuteropaulina en $1 \mathrm{Tm} 1,2 ; 2 \mathrm{Tm}, 1,2 ; \mathrm{y} \mathrm{Tt}$ 1,4. El término $\tau \varepsilon ́ x v o u$ se distingue de viós que también se traduce como hijo; el primer término establece la relación de filiación entre los seres humanos, mientras que el segundo con Dios; véase, por ejemplo, Rm 8,14-15; 2Co 6,18; Ga 3,26, etc. 
y como tal se refiera a los miembros de las comunidades, por ejemplo, en 1Co 4,15 o en Ga 4,19.

En el v. 10, Pablo explicita la petición que ya había anunciado utilizando una vez más el verbo $\pi a p a x a \lambda \omega \tilde{\omega}:$ "te ruego a favor de mi hijo a quien engendré entre cadenas". De acuerdo con la interpretación tradicional de la Carta, Onésimo es un hombre convertido a la fe durante la prisión de Pablo; de hecho, cuando lo denomina "hijo engendrado entre cadenas", está especificando una nueva relación establecida entre él y Onésimo ${ }^{29}$. La imagen que utiliza Pablo, "engendrado" respecto de Onésimo es muy sugerente, pues a Filemón y a la comunidad les queda claro lo que significa Onésimo para Pablo, el lazo estrecho e íntimo, así como la nueva condición de Onésimo ${ }^{30}$.

Ciertamente, Onésimo - para Pablo- ya no es reconocido como esclavo sino como "hijo", alguien que ha llegado a la vida de la fe por y a través de él, es decir, como un nuevo cristiano. El Apóstol lo hace saber de este modo enfático a Filemón y a la Iglesia que se reunía en su casa ${ }^{31}$.

La conversión de Onésimo es, al parecer, una noticia nueva para Filemón y la iglesia que se reunía en su casa. Esto significa que, probablemente, no todos los de la casa de Filemón habían aceptado la fe cuando este lo hizo ${ }^{32}$. Si Pablo está diciendo que engendró a Onésimo entre cadenas, la conversión de Filemón (cabeza de familia-patrón) no implicó a todos los miembros de la casa.

Si Onésimo, su esclavo, no era cristiano cuando estaba con Filemón, ahora que regresa con la Carta pasa a formar parte de la comunidad que se reúne en su casa, más aún, en la misma condición que Filemón, es decir, de "hermano", pues él también fue convertido a la fe por Pablo. Con este argumento, Pablo está presentando la nueva realidad de Onésimo, el tema de la fraternidad en Cristo que ha de existir entre Filemón y Onésimo. Ambos son cristianos y deben ser iguales "tanto en la carne como en el Señor" (v. 16) ${ }^{33}$.

En el v. 11 se observa el juego de palabras que hace Pablo: Onésimo, esclavo "útil", si antes era considerado inútil, ahora es una persona que les favorece a los dos.

\footnotetext{
${ }^{29}$ Lohse, Colossians and Philemon, 199.

${ }^{30}$ De la Serna, "Un aporte a la cronología de las cartas paulinas", 4. Caballero, "Retórica y teología. La Carta a Filemón”, 454.

${ }^{31}$ Aquí es interesante ver que la imagen de "hijo" empleada por Pablo para referirse al nuevo converso a la fe cristiana tiene un referente en el judaísmo rabínico; allí se usaba la imagen de padre e hijo con referencia al maestro y el estudiante de la Torah. Así mismo, en las religiones mistéricas el mistagogo era considerado el padre del iniciado. Véase a Lohse, Colossians and Philemon, 200.
}

${ }^{32}$ Vidal, Las cartas originales de Pablo, 322.

${ }^{33}$ Crossan y Reed, En busca de Pablo, 142. 


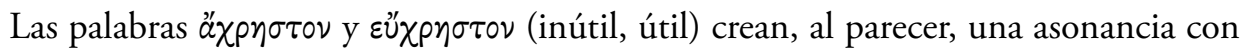

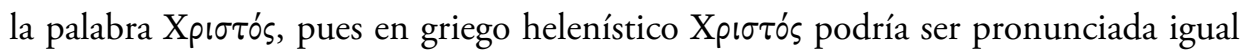

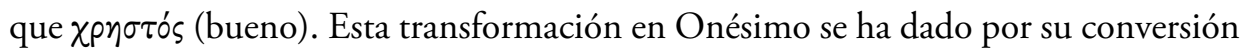
a Cristo ${ }^{34}$; hay un cambio en la vida de este, y Pablo se refiere al hecho señalando además qué significa ser cristiano.

Quizás Pablo quiere decirle a Filemón que es más "útil" un hombre libre en Cristo que un esclavo. Él está dando a entender que Onésimo, ahora cristiano, hace honor a su nombre "útil", que su pasado queda atrás, y que solo cuenta el presente, determinado por su nueva condición ${ }^{35}$.

\section{Probatio $^{36}$. La razón para el regreso de Onésimo (vv. 12-16]}

${ }^{13} Y o$ deseaba retenerlo conmigo para que me sirviera en tu lugar, en estas cadenas por el Evangelio; ${ }^{14}$ más sin tu consentimiento no he querido hacer nada, para que esta buena acción tuya no fuera forzada sino por libre voluntad. ${ }^{15}$ Pues tal vez fue alejado de ti por algún tiempo, precisamente para que lo recuperaras para siempre, ${ }^{16}$ y no como esclavo sino más que un esclavo, un hermano querido, que siéndolo para mi, cuanto más para ti, tanto en la carne como en el Señor.

${ }^{12}$ Te lo envio de vuelta, a él, mi propio corazón (entrañas).

En este versículo, Pablo le insiste a Filemón sobre la nueva condición de Onésimo, argumentando que ahora es parte de "mi propio corazón, entrañas". Esta identificación señala que Onésimo ha de ser tratado según su nueva condición. Sin embargo, deja que Filemón actúe de acuerdo con su voluntad. Así mismo, el verbo ảvé $\pi \varepsilon \mu \psi \alpha$-que está en aoristo epistolar- tiene significado presente, "enviar de vuelta", y carece de carácter legal, como tal vez sucede en Lc 23,7 o en Hch 23,7.

Este punto es importante, pues significa que Pablo no está enviando a Onésimo de vuelta por un cumplimiento jurídico, o-como varios autores han propuesto- por considerarlo un "esclavo fugitivo". Pablo tampoco está pidiendo "un favor" para Onésimo; él especifica su nueva condición, el lugar que ocupa y el significado que tiene para él: como "mi propio corazón” ${ }^{37}$. Así, el texto muestra que Onésimo no es

\footnotetext{
${ }^{34}$ Lohse, Colossians and Philemon, 200.

${ }^{35}$ Ibíd., 201.

${ }^{36}$ En estos versículos la probatio cumple la función de argumentar las razones por las cuales es válida la propositio, es decir, aquello que Pablo le pide a Filemón para Onésimo.

${ }^{37}$ Osiek, Philippians, Philemon, 137.
} 
un esclavo fugitivo y, por tanto, no se puede inferir que ha cometido un delito, razón por la cual huye, tal como se ha pensado tradicionalmente.

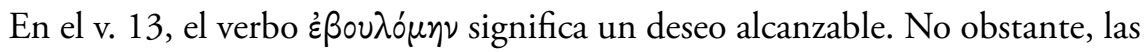
palabras de Pablo se pueden ver como una estrategia retórica de persuasión que busca suscitar la aceptación de su petición de los vv. 10-12. El lenguaje empleado manifiesta el valor que Onésimo tiene para el anuncio del Evangelio; por el "servicio" que él presta no solo a Pablo en cadenas por el Evangelio, sino también a Filemón y a la comunidad.

Si Onésimo sirve o es útil a Pablo, entonces es como si el mismo Filemón le estuviera sirviendo al Apóstol en un momento de necesidad ("entre cadenas"). Este servicio, de acuerdo con el presente subjuntivo activo, tercera persona del singular ( referir también ocasionalmente al servicio que Onésimo presta a la comunidad ${ }^{38}$. Así, cuando Pablo expresa a Filemón su deseo de retener a Onésimo, le está mostrando el valor que tiene tanto para él mismo como para la comunidad.

En el v. 14, Pablo apela a la libertad y buena acción de Filemón, si este decide dejar que Onésimo le sirva en su lugar. Ahora bien, Pablo ya le había dicho que él podía retener a Onésimo (v. 8); sin embargo, cuenta con su aprobación, dejando a Filemón la decisión de hacer una buena y libre acción por voluntad propia: es decir, hacer un servicio por el Evangelio, ya que Pablo conoce de la fe y caridad de Filemón para con los santos (v. 7) ${ }^{39}$.

El adjetivo Éxoú todo el corpus paulino ${ }^{40}$. Podría ser porque Pablo quiere que las motivaciones de fondo para que Filemón actúe no sean una norma externa: ya existen normas que permiten la manumisión de un esclavo, pero este no es el razonamiento de Pablo. Aquí se está haciendo referencia a la libertad interna de Filemón, es decir, a su obrar sin presión alguna, por su propio querer e interés. En el fondo Pablo está forzando de otra manera a Filemón, proponiéndolo como ejemplo a la comunidad (pues aparece ante ella como gran patrón, servidor, hombre de caridad y fe reconocida), y ahora tiene la oportunidad de demostrarlo.

En síntesis, en los vv. 10-14, Pablo señala el objetivo de la Carta: Filemón tendrá que acoger a Onésimo, ya no como esclavo sino como a un hermano (vv. 15-16). El que Pablo se atribuya como propia la pertenencia de Onésimo quiere decir que la

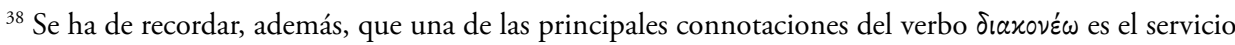

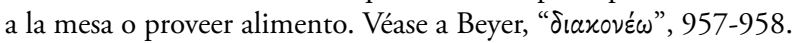

${ }^{39}$ Osiek, Philippians, Philemon, 138.

${ }^{40}$ Lohse, Colossians and Philemon, 202.
} 
conversión establece un vínculo de fraternidad y reconocimiento de la igualdad que en Cristo existe entre Pablo, Onésimo y Filemón ${ }^{41}$.

En general, estos versículos dejan ver la maestría con que Pablo hace uso de la persuasión retórica. En primer lugar, Pablo "ruega" a Filemón por Onésimo; posteriormente le expresa las razones por las cuales ha de acceder a su petición; y por último le muestra que la decisión de aceptar o no a Onésimo, finalmente está en sus manos. En este sentido, Pablo también ha de ser coherente con lo que le dice a Filemón, y por ello no puede forzarlo a tomar una decisión.

En el v. 15, el lenguaje de Pablo es muy cuidadoso: utiliza, por ejemplo, el

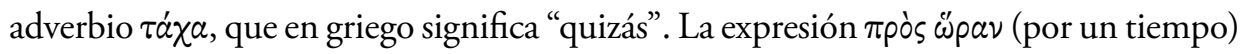

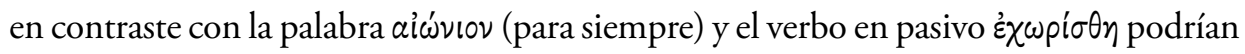
indicar que Pablo piensa y quiere mostrar que el alejamiento de Onésimo ha sido causado por Dios, para bien de todos. La separación ha sido por poco tiempo, pero la nueva relación en Cristo será para siempre ${ }^{42}$. Señala así que en Cristo se establecen relaciones de fraternidad que superan los vínculos propuestos por el contexto socio cultural. De esta forma, se genera una relación de igualdad entre Onésimo y Filemón.

En el v. 16, la partícula comparativa ẃs señala la relación establecida por Pablo entre Filemón y Onésimo. El Apóstol denomina a Onésimo "hermano querido", más que esclavo, indicando así el comportamiento que ha de darse entre ellos. La función del superlativo $\mu \alpha \dot{\lambda} \lambda เ \tau \tau \alpha$ es exaltar el sentido de esta nueva relación en Cristo ${ }^{43}$. No se desconoce la condición de esclavo de Onésimo, ni tampoco Pablo hace referencia a esta; solo menciona que la relación entre ellos ha de ser mejor, no solo en la "carne" sino en el "Señor".

La condición cristiana le añade un plus al vínculo que se ha establecido aquíí.

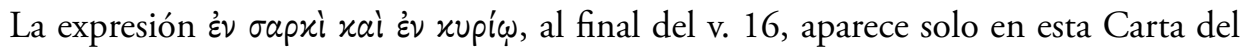
corpus paulino. Así, según Pablo, Onésimo pasa de ser esclavo a ser hermano querido; el vínculo entre ellos debe estar marcado por el amor cristiano ${ }^{45}$.

\footnotetext{
${ }^{41}$ En la misma línea ganar a Onésimo para Cristo es recuperarlo para bien de Filemón y de Pablo, gracias a la conversión, a que ha sido engendrado como a un hijo. No hay que olvidar que Pablo reconoce la autoridad de Filemón sobre Onésimo; además se describe una situación de pérdida y recuperación, es decir, como una reconciliación.

${ }^{42}$ Lohse, Colossians and Philemon, 202, y Osiek, Philippians, Philemon, 138.

${ }^{43}$ Lohse, Colossians and Philemon, 203; Osiek, Philippians, Philemon, 139.

${ }^{44}$ Crossan, y Reed, En busca de Pablo, 141.

${ }^{45}$ Caballero, "Retórica y teología. La Carta a Filemón”, 457-458.
} 


\section{Peroratio $^{46}$. Epilogo (vv. 17-22)}

1. Bienvenida, regreso (vv. 17-19)

${ }^{17}$ Asi que, si me tienes por compañero, recibelo como a mi mismo.

En este versículo, el conector oũv articula toda la argumentación dada hasta aquí y el tema de la Carta, que no es otro que la cogida de Onésimo por parte de Filemón.

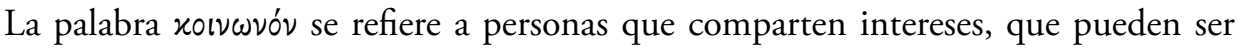
económicos o de otra índole ${ }^{47}$. El vínculo en la Carta es la fe y la caridad, bases sobre las que Pablo plantea su petición a Filemón; el amor brindado a Onésimo será considerado como dado al mismo Pablo ${ }^{48}$.

En el v. 17, al parecer, Pablo hace uso de un paralelismo temático con el v. 12, pues reaparece la primera persona del singular como motivación para la decisión que debe tomar Filemón. Si finalmente Filemón no quiere acoger a Onésimo por alguna razón, Pablo le impele a que lo haga por él mismo; así lo indica la expresión: si me tienes como algo unido a ti acógele como a mi mismo (v. 17). Evidentemente, el Apóstol está usando aquí el recurso al símil; Pablo se asimila a Onésimo, para que Filemón acepte su proposición ${ }^{49}$.

${ }^{18}$ y si en algo te trato injustamente (perjudicó), o algo te debe, cárgalo a mi cuenta.

En el v. 18 parece que los verbos ỏ $\phi \varepsilon i ́ \lambda \varepsilon ı$ y $\varepsilon^{2} \lambda \lambda o^{\prime} \gamma \alpha$ cumplen una función retórica judicial, pues Pablo quiere obrar en justicia con Filemón. De hecho, el término દ̇ $\lambda \lambda o_{\gamma} \alpha$ destaca con mayor fuerza la súplica de Pablo $^{50}$, porque si Onésimo causó algún daño voluntariamente a Filemón, Pablo se ofrece a resarcirlo en su nombre. Así mismo,

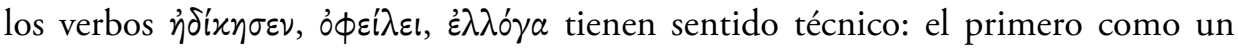
trato injusto dado a alguien, el segundo con referencia a una deuda financiera y el tercero como cargar un pago a la cuenta de alguien.

Este estilo corresponde -como se ha mencionado-al género retórico judicial, probablemente para establecer una concordancia con las palabras que luego Pablo dirá

${ }^{46}$ En esta parte del texto, Pablo recapitula lo expuesto en los versículos anteriores, y ruega a Filemón por la aceptación de Onésimo. Esta sección se conoce como una peroratio.

${ }^{47}$ Caballero, "Retórica y teología. La Carta a Filemón”, 460.

${ }^{48}$ Lohse, Colossians and Philemon, 203-204.

${ }^{49}$ Esto quiere decir que si Filemón finalmente no quiere aceptar a Onésimo como "hermano querido", Pablo apela a la relación que existe entre ellos, asimilándose a Onésimo y presentándolo como si fuera él mismo; Onésimo debería ser, a los ojos de Filemón, no un esclavo sino un hermano en Cristo, al mismo nivel de Pablo.

${ }^{50}$ Caballero, "Retórica y teología. La Carta a Filemón”, 462. 
a Filemón: él mismo se debe a Pablo (v.19). Al parecer, lo usa para señalar que su fin es obrar con justicia, y por ello sale en defensa de Onésimo.

En el texto no se afirma que Onésimo haya tomado algo de Filemón; solo se dice que, si le ha causado algún daño, "si en algo te perjudicó o te debe", nada más.

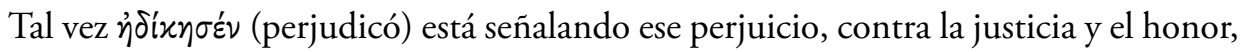
dado que Filemón es cabeza de familia y naturalmente puede estar juzgando la realidad de Onésimo, como lo haría un paterfamilias de su tiempo y contexto ${ }^{51}$.

Este verbo $\eta^{\delta} \delta \dot{x} \eta \sigma \varepsilon v$, que está en aoristo activo, tercera persona del singular, puede significar hacer un mal o engañar. No necesariamente se refiere a haber tomado algo o haber robado, como varios autores tradicionalmente han interpretado ${ }^{52}$. Alude a un daño, a un acto deshonesto que quizás Onésimo causó a Filemón. Es decir, si Onésimo ha engañado a Filemón o ha hecho algo en contra del honor de este, Pablo quiere señalar que su defensa podría estar por encima de los parámetros establecidos socialmente (honor y deshonor) y de esta manera restablecer la justicia (cristianamente hablando).

${ }^{19}$ Yo Pablo escribo con mi mano, yo pagaré, por no decir que tú mismo estás en deuda conmigo, pues tú mismo te me debes.

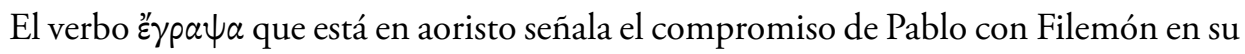
intercesión por Onésimo. El verbo da una fuerza significativa a las palabras de Pablo en la Carta, garantizando que él mismo escribe ${ }^{53}$. Así mismo, el verbo ả $\pi 0 \tau i ́ \sigma \omega$, en futuro, está relacionado con el versículo anterior, pues asume en su propia cuenta la posible deuda causada por Onésimo ${ }^{54}$. El verbo también presenta un matiz judicial, ya que tiene el sentido de "compensación" por el daño causado.55

No obstante, el posible carácter judicial que tuviera la deuda de Onésimo, este queda supeditado a la deuda que tiene Filemón con Pablo: "Tú mismo te me debes". De esta manera, queda expuesta la relación de Pablo y Filemón, así como el sentido de las deudas causadas, es decir, que en ese caso la deuda de Filemón sería mayor, de tipo espiritual, por encima de la judicial. Lo anterior se expresa mediante la diferencia

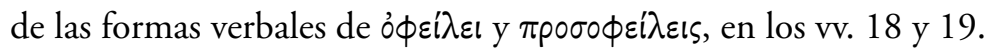

${ }^{51}$ Osiek, Philippians, Philemon, 140.

52 Pastor, Corpus paulino II, 197; Sánchez Bosch, Escritos paulinos, 366 (el autor dice que le debía dinero y le procuró algún otro daño); Barclay, Comentario al Nuevo Testamento. Comentario al Nuevo Testamento. Vol. 12. 1a y 2a Timoteo, Tito, Filemón, 222.

${ }^{53}$ Lohse, Colossians and Philemon, 204.

${ }^{54}$ Caballero, "Retórica y teología. La Carta a Filemón”, 462.

${ }^{55}$ Lohse, Colossians and Philemon, 204. 


\section{2. Último motivo (v. 20) una petición final}

${ }^{20} \mathrm{Si}$, hermano, hazme este favor en Cristo. Alivia mi corazón (entrañas) en Cristo.

La partícula vaí aparece como un énfasis en la petición de Pablo. Este uso es propio del estilo paulino, como también aparece en Flp 4,3. El verbo óvaíuฑv es un optativo aoristo muy raro en el Nuevo Testamento ${ }^{56}$, cuyo sentido está unido a una petición por sí mismo, y enfatiza la petición de Pablo por Onésimo, como si fuera para él o hecha a él mismo. Es fundamental subrayar que Pablo se refiere a Filemón como ả $\delta \varepsilon \lambda \phi \varepsilon ́$ (hermano). Su petición no se hace en nombre propio, sino en nombre del Señor, a quien pone Pablo como intermediario de su petición.

El imperativo final puede estar relacionado con el sentido del ser cristiano: "aliviar el corazón" es poner en obra la fe y la caridad que han de distinguir a los cristianos; por esta razón la frase está muy unida al v. 7. Si Filemón finalmente decide escuchar a Pablo, según el argumento paulino, será en nombre de Cristo y no porque Pablo así se lo pida ${ }^{57}$, y de igual forma estará aliviando las cadenas y adversidades que el Apóstol está sufriendo por el Evangelio.

La close reading aquí presentada demuestra que Pablo quiso incidir en la decisión de Filemón respecto de Onésimo para que esta fuera tomada correctamente desde el punto de vista cristiano; su petición parece, de hecho, una súplica en nombre de Cristo. Pablo insiste en su petición, llamando a Filemón hermano, recordándole su relación fraterna en Cristo. También le pide que haga menos pesado su corazón y le quite una carga de encima; no por él, sino por Cristo. Pablo busca persuadir a Filemón por varios medios; su argumentación prevé, además, que en el caso de que Filemón no quiera obrar consecuentemente con su fe, él se vea impelido por la comunidad que escucha también la solicitud del Apóstol.

En este sentido, la Carta se puede interpretar también como una enseñanza para la comunidad, una instrucción sobre las actitudes que se esperan de sus miembros en circunstancias análogas. En su Carta, Filemón puede leer así al menos dos buenas razones para obrar según la petición de Pablo: el mismo Pablo con sus argumentos y la comunidad reunida en su casa que escucha lo mismo.

\footnotetext{
${ }^{56}$ Lohse, Colossians and Philemon, 205; Osiek, Philippians, Philemon, 141.

${ }^{57}$ Caballero, "Retórica y teología. La Carta a Filemón”, 465.
} 


\section{Onésimo y Filemón, entre fraternidad e igualdad (observaciones conclusivas)}

El objetivo último de la persuasión paulina en la Carta a Filemón es la reconfiguración de las relaciones de los miembros de la iglesia que se reúnen en su casa (Flm 1-2), para que ellas se asimilen al paradigma del vínculo fraterno entre Onésimo y Filemón. En esta Carta, sin embargo, las estructuras que sostienen las diferencias socioculturales, por ejemplo, entre patrón y esclavo, no se ponen en tela de juicio. La Carta, además, no ofrece suficientes indicios para explicar por qué razón Pablo no se pronuncia contra este statu quo.

La argumentación paulina, es decir, las pruebas que sustentan su petición en favor de Onésimo insisten repetidas veces, por el contrario, en la transformación de las motivaciones que se dirigen a su paterfamilias y en la consecuente reconfiguración de las relaciones de los miembros de su "casa".

Cuando Pablo le pide a Filemón que acepte a Onésimo como un hermano querido, le está diciendo que independientemente de la posición social de Onésimo (esclavo), en el ámbito de las relaciones en Cristo, los dos (Filemón y Onésimo) tienen la misma condición. Los roles en la sociedad no pueden ser una excusa para negar la dignidad humana y más aún para desconocer al otro como hermano; tampoco para establecer relaciones jerárquicas por el estatus social.

Esta es posiblemente la razón por la cual Pablo no busca cambiar la condición social de los esclavos. Más allá del cargo, del rol social, del nivel económico y del trabajo que desempeñe una persona, desde la perspectiva cristiana, es decir, en Cristo, todos los seres humanos están al mismo nivel (Filemón y Onésimo).

Pablo persigue resignificar las relaciones entre las partes, especialmente entre las que el sistema sociocultural impone como desiguales. Ahora bien, a la luz de la probatio paulina en la Carta [a Filemón], ¿se podría eventualmente modificar el statu quo sociocultural del esclavo sin reconocerlo antes como hermano?

La respuesta que se lee entre las líneas de la argumentación paulina afirma que, si las relaciones comunitarias no se resignifican desde dentro a partir de la experiencia del amor fraterno en Cristo, los miembros de la comunidad seguirán manteniendo vivos los vínculos desiguales (según las directrices del poder de turno). Las comunidades cristianas se vuelven contraculturales efectivamente cuando sus transformaciones sociales surgen de la experiencia interna (interior) de sentir y ver al otro como hermano, con la misma dignidad en Cristo, y no cuando permanecen atadas a experiencias externas.

Este ejercicio de lectura, comprensión, reflexión y meditación de la Carta a Filemón se llevó a cabo durante un año con las comunidades de Casitas Bíblicas en Bogotá. El interés -tal como se fue desarrollando a lo largo de este escrito- fue señalar 
cómo la Carta a Filemón propone y plantea caminos para establecer el perdón y la reconciliación.

El statu quo dentro de las comunidades y la vida social no se modificará si solo se plantean soluciones desde fuera; la reconfiguración de las relaciones será un camino para poner la casa (oĩxos) en orden desde un nuevo estilo de vida y la resignificación de las relaciones en la comunidad (iglesia). Cada reflexión y estudio dado en este texto se fue realizando con la pregunta de fondo de cómo proponer un camino de perdón y reconciliación a partir de la propuesta paulina en la Carta a Filemón: la "reconfiguración de las relaciones".

\section{Referencias}

Barclay, William. Comentario al Nuevo Testamento. Vol. 12. 1a y $2^{a}$ Timoteo, Tito, Filemón. Barcelona: Clíe, 2009.

Beyer, H. W. “dıaxovéw”. En Grande Lessico del Nuovo Testamento. Vol. II, editado por F. Kittel y G. Friedrich, 951-966. Brescia: Paideia, 1965.

Borg, Marcus y John Dominic Crossan. El primer Pablo. La recuperación de un visionario radical. Estella (Navarra): Verbo Divino, 2009.

Caballero, Juan Luis. "Retórica y teología. La Carta a Filemón”. Scripta Theologica 37 (2205): 441-474.

Crossan, John Dominic y Jonathan L., Reed. En busca de Pablo. Estella (Navarra): Verbo Divino, 2006.

De la Serna, Eduardo. "Un aporte a la cronología de las cartas paulinas". Theologica Xaveriana Vol. 70 (2020): 1-22.

De Vaux, Roland. Instituciones del Antiguo Testamento. Barcelona: Herder, 1964.

Elliott, Scott S., “'Thanks, but no Thanks': Tact, Persuasion, and the Negotiation of Power in Paul's Letter to Philemon", NTS 57 (2011): 51-64.

Fernández Vega, Pedro Ángel. La casa romana. Madrid: Akal, 2003.

Fitzmyer, Joseph. "Carta a Filemón". En Nuevo comentario bíblico "San Jerónimo". Nuevo Testamento y artículos temáticos, editado por Raymond E. Brown, Joseph A. Fitzmyer, y Roland E. Murphy, 419-421. Estella (Navarra): Verbo Divino, 2004.

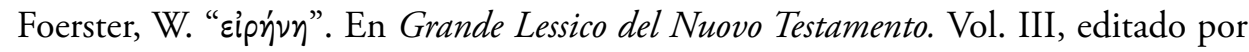
F. Kittel y G. Friedrich, 191-195. Brescia: Paideia, 1965. 
Lohse, Eduard. Colossians and Philemon. Philadelphia (PA): Fortress Press, 1997.

Miguez, Néstor. “Carta a Filemón”. En Comentario bíblico latinoamericano, dirigido por Armando J. Levoratti con colaboración de Elsa Tamez y Pablo Richard, 1043-1048. Estella (Navarra): Verbo Divino, 2007.

Miquel, Esther. Qué se sabe del Nuevo Testamento desde las ciencias sociales. Estella (Navarra): Verbo Divino, 2011.

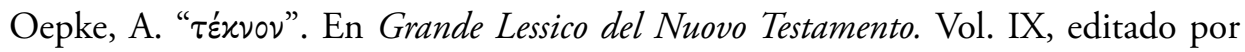
F. Kittel y G. Friedrich, 223-276. Brescia: Paideia, 1965.

Osiek, Carolyn. Philippians, Philemon. Nashville (TN): Abingdon Press, 2000.

Osiek, Carolyn; Margaret MacDonald; y Janeth Tulloch. El lugar de la mujer en la Iglesia primitiva. Salamanca: Sígueme, 2007.

Pastor, Federico. Corpus paulino II. Bilbao: Desclée De Brouwer, 2005.

Philips, William. La esclavitud desde la época romana hasta los inicios del comercio transatlántico. Madrid: Siglo XXI, 1989.

Pitta, Antonio. "Come si persuade un uomo? Analisi retorico-letteraria della lettera a Filemone". En Oltre il racconto. Esegesi ed ermeneutica: alla ricerca del censo, editado por C. Marcheselli-Casale, 93-107. Napoli: M. D’Auria Editore, 1994.

Sánchez Bosch, Jordi. Escritos paulinos. Estella (Navarra): Verbo Divino, 2009.

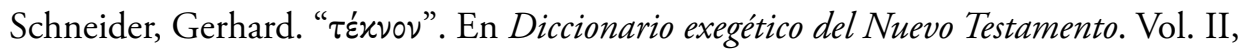
editado por H. Balz y G. Schneider, 1702-1705. Salamanca: Sígueme, 2012.

Ska, Jean Louis. Introducción a la lectura del Pentateuco. Claves para la interpretación de los cinco primeros libros de la Biblia. Estella (Navarra): Verbo Divino, 2001.

Vidal, Senen. Las cartas originales de Pablo. Villadolid: Editorial Trois, 1996.

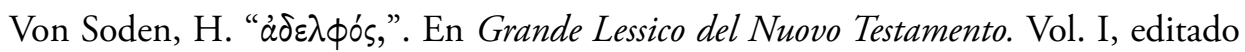
por F. Kittel y G. Friedrich, 385-392. Brescia: Paideia, 1965.

Witherington, Ben. The Letters to Philemon, the Colossians and the Ephesians. A Socio-Rhetorical Commentary on the Captivity Epistles. Grand Rapids (MN): Eerdmans, 2007.

Zimmermann, Heinrich. Los métodos histórico-criticos en el Nuevo Testamento. Madrid: Biblioteca de Autores Cristianos, 1969. 